\section{Performance Evaluation of a Banana Pseudostem Chopper}

\author{
Jun $\mathrm{Li}^{1,2}$, Zhongyue $\mathrm{Lu}^{1}$, Hamza Elkhouchlaa ${ }^{1}$, Jiaquan Lin ${ }^{1}$, \\ Can $\mathrm{Li}^{1}$, Hao Wang ${ }^{1}$, and Zhou Yang ${ }^{2,3}$
}

AdDitional INDEX wORDs. blade cutting type, feeding angle, Musa nana, operating parameters, soil improvement

Summary. The method of returning banana (Musa nana) pseudostems to the field can effectively maintain and improve the level of organic matter in the soil. In this article, we show that a small vertical-type banana pseudostem chopper can be used in banana plantations that do not need to be replanted. The aim of this study was to investigate the relationship among the blade type, cutting force, and cutting power. The effects of the blade roll angles, pitch angles, and feeding angles on the crushing qualification rate and crushing efficiency were obtained by comparing the decomposition characteristics of a banana pseudostem before and after crushing. The results showed that the arc-shaped blade exhibited the smallest cutting force and cutting power consumption. The maximum crush qualification rate and crush efficiency were obtained when the roll angle was $12^{\circ}$, the pitch angle was $-5^{\circ}$, and the feeding angle was $5^{\circ}$. The weight reduction rate and average decomposition rate of the crushed pseudostem were 2.73 and 3.61 times greater than those of natural decomposition, respectively. The results can be used as a reference for the design and optimization of banana pseudostem choppers.

$\mathrm{I}$ $\mathrm{n}$ recent years, agricultural wastes such as banana (Musa nana) leaves, pseudostems, and pericarps have attracted increasing attention from experts and scholars (Ozbay et al., 2019; Raymundo et al., 2014). As the main byproduct of banana plantations, banana pseudostems are a widely used biological resource that can effectively improve soil fertility, maintain soil organic matter levels, and enhance soil

Received for publication 25 Aug. 2020. Accepted for publication 5 Feb. 2021

Published online 24 March 2021

${ }^{1}$ College of Engineering, South China Agricultural University, Guangzhou, 510642, China

${ }^{2}$ Key Laboratory of Key Technology on Agricultural Machine and Equipment, Ministry of Education, South China Agricultural University, Guangzhou, Guangdong, 510642, China

${ }^{3}$ Guangdong Provincial Key Laboratory of Conservation and Precision Utilization of Characteristic Agricultural Resources in Mountainous Areas, Jiaying University, Meizhou, 514015, China

This research was supported by funds earmarked for the Key-Area Research and Development Program of Guangdong Province (Accession No. 2019B020223002), National Key R\&D Program of China (Accession No. 2018YFD0201100), and China Agriculture Research System (Accession No. CARS-31-10).

J.L. and Z.Y. are Professors.

Z.Y. is the corresponding author. E-mail: yangzhou@ scau.edu.cn.

This is an open access article distributed under the $\mathrm{CC}$ BY-NC-ND license (https://creativecommons.org/ licenses/by-nc-nd/4.0/).

https://doi.org/10.21273/HORTTECH04720-20 nutrients (Basak et al., 2015; Huang et al., 2020; Siemens et al., 2003). The banana planting area in China is $\approx 396,000$ ha. If the amount of banana pseudostems is calculated as 94 $\mathrm{t} \cdot \mathrm{ha} \mathrm{a}^{-1}$, the total biomass of banana pseudostems is as high as $37 \mathrm{t}$ per year (Wang et al., 2017). Over the years, due to the lack of efficient machinery to return banana pseudostems to the field, most plantation stacking or incinerating, which has high labor intensity and low efficiency (the time it takes to crush a hectare of banana pseudostems) and introduces diseases to the banana plantation if it is not handled in time (Wang et al., management adopts the method of
2017). In addition, the incineration and stacking of banana pseudostems deteriorate the ecological environment and do not allow the full use of organic matter and its nutrients, which will result in a loss of pseudostem resources (Liu et al., 2014).

The main methods of pseudostem return include direct return, indirect return, and biochemical decomposition. In direct return, the pseudostem is crushed and buried in the field, which is easy to do, highly efficient, and low in energy consumption. Direct return can also store water and improve soil fertility. In indirect return, the pseudostem is crushed, fermented, and finally returned to the field in the form of manure or biogas residue. In biochemical decomposition, the crushed pseudostem is mixed with bacterial agents and nitrogen fertilizer to produce an organic mature fertilizer after a high-temperature treatment. Among the three methods of pseudostem return, the direct return is simpler and more crushing efficient by smashing the pseudostem and mixing with the soil directly ( $\mathrm{Li}$ et al., 2017). The existing research on pseudostem return has mainly focused on sorghum (Sorghum bicolor), cotton (Gossypium sp.), sugarcane (Saccharum officinarum), wheat (Triticum aestivum), and corn (Zea mays) (Chen et al., 2004; Igathinathane et al., 2009, 2010,2011 ), including the exploration of the impact of the cutter roller speed, cutting mode, and moisture ratio on the cutting performance and power consumption (Bakeer et al., 2013; Duval et al., 2011; Ghahraei et al., 201 1; Kakahy et al., 2013, 2014; Mathanker et al., 2015). The design of

\begin{tabular}{llll}
\hline $\begin{array}{l}\text { Units } \\
\begin{array}{l}\text { To convert U.S. to SI, } \\
\text { multiply by }\end{array}\end{array}$ & U.S. unit & SI unit & $\begin{array}{l}\text { To convert SI to U.S., } \\
\text { multiply by }\end{array}$ \\
\hline 0.4047 & $\mathrm{acre}(\mathrm{s})$ & $\mathrm{ha}$ & 2.4711 \\
0.3048 & $\mathrm{ft}$ & $\mathrm{m}$ & 3.2808 \\
0.0283 & $\mathrm{ft}^{3}$ & $\mathrm{~m}^{3}$ & 35.3147 \\
0.7457 & horsepower & $\mathrm{kW}$ & 1.3410 \\
2.54 & inch $(\mathrm{es})$ & $\mathrm{cm}$ & 0.3937 \\
25.4 & inch $(\mathrm{es})$ & $\mathrm{mm}$ & 0.0394 \\
16.3871 & inch & $\mathrm{cm}^{3}$ & 0.0610 \\
0.4536 & $\mathrm{lb}$ & $\mathrm{kg}$ & 2.2046 \\
4.4482 & $\mathrm{lbf}$ & $\mathrm{N}$ & 0.2248 \\
1.3558 & $\mathrm{lbf} \mathrm{ft}$ & $\mathrm{N} \cdot \mathrm{m}$ & 0.7376 \\
28.3495 & $\mathrm{oz}$ & $\mathrm{g}$ & 0.0353 \\
28,350 & $\mathrm{oz}$ & $\mathrm{mg}$ & $3.5274 \times 10^{-5}$ \\
0.9072 & ton $(\mathrm{s})$ & $\mathrm{t}$ & 1.1023 \\
2.2417 & ton $(\mathrm{s}) / \mathrm{acre}$ & $\mathrm{t} \cdot \mathrm{h}^{-1}$ & 0.4461 \\
$\left({ }^{\circ} \mathrm{F}-32\right) \div 1.8$ & ${ }^{\circ} \mathrm{F}$ & ${ }^{\circ} \mathrm{C}$ & $\left({ }^{\circ} \mathrm{C} \times 1.8\right)+32$ \\
& & & \\
\hline
\end{tabular}


a banana pseudostem chopper, when compared with the chopper design used with other crops, must also consider the characteristics of a pseudostem with a large diameter, high moisture ratio, and strong plant fiber. A large tractor-mounted banana pseudostem chopper has the advantages of directly returning the pseudostem to the field, high efficiency in returning the residue to the field, and high crushing qualification rate (the ratio of crushed qualified pseudostem to the total crushed pseudostem). Such a chopper is widely used in large-scale banana plantations that require cleaning and replanting (Akdemir, 2013). Zhang's team (Zhang, 2019) designed a hydraulically driven machine for banana pseudostem chopping and recycling (direct return). The cutting system adopts a cutting method similar to the movement principle of the double-roller. The disc sawtooth cutter is evenly distributed across two transmission shafts, and hydraulic power is used as the power source to transfer the power to the cutting system. This machine can chop 900 plants/h (the average height of the banana tree is $2.1 \mathrm{~m}$ ); i.e., $\approx 0.35$ $\mathrm{ha} \cdot \mathrm{h}^{-1}$, with a crushing qualification rate of more than $84 \%$. Zhang's team performed field experiments with a slide-cutting and an anti-tangling banana pseudostem chopper, and the results showed that the effect of various factors on the crushing rate and power consumption of the banana pseudostem from large to small was in the following sequence: rotation speed of the crushing cutter roller > rotation speed of the stubble cutter roller $>$ forward speed of the machine (Zhang et al., 2018). Wang's team developed a precut banana pseudostem chopper that adopted the combined crushing method of precutting segment knife and a postcrushing knife to reduce winding and binding of the banana pseudostem fiber in the machine (Wang et al., 2017). Zhu's team developed a banana pseudostem chopper that could complete the breaking, crushing, weeding, overturning, covering, and compaction operations of the entire banana plant and soil at once (Zhu et al., 2011).

At present, a tractor-mounted banana pseudostem chopper is only suitable for large-scale banana plantations on flat lands that require cleaning and replanting, and it has a high power consumption. For banana plantations that do not need to be cleaned and replanted, it is more suitable to use a light and small mobile banana pseudostem chopper. Therefore, this article presents a small vertical banana pseudostem chopper that was evaluated for blade type, blade installation angle, and feed angle. The cutting force, cutting power, crushing qualification rate, and crushing efficiency were used as the test parameters. The experiment explored the role of key operating parameters on the return of chopped banana pseudostems to the field, which can provide a reference for the design and optimization of future banana pseudostem choppers.

\section{Materials and methods}

Materials. The experiment was performed at the banana test site of South China Agricultural University, Guangzhou, China. The average temperature during the experiment was $24{ }^{\circ} \mathrm{C}$, and the average relative humidity was $86 \%$. The conditions of the plant material were determined as follows: there were 45 pseudostem samples, which were named 'Zhongjiao No. 9'; the average plant height of the banana pseudostem was $2.8 \mathrm{~m}$; the average diameter was $200 \mathrm{~mm}(\mathrm{SD}=$ 14.06); the average moisture content was $82.1 \%$; the average age was 1 year old; the pseudostem was thick, the upper and lower parts were uniform, and the leaves were wide. The test machine was a small vertical banana pseudostem chopper. The main test equipment included a dynamic torque sensor $[ \pm 100 \mathrm{~N} \cdot \mathrm{m}$ range, $0.001-0.005$ $\mathrm{N} \cdot \mathrm{m}$ accuracy (ZH07-50Z; Odek Electronics Co., Shenzhen, China)], a tachometer (UT372; UNI-T Co., Dongguan, China), a protractor, and an electronic weighing instrument. The details of the chopper engine are shown in Table 1.

As shown in Fig. 1, the small vertical banana pseudostem chopper mainly consisted of a pseudostem holding mechanism, a powertrain, and a cutting device. The pseudostem holding mechanism is composed of a U-shaped arm, a telescopic rod, a connecting rod, and a guiding rod. The symmetrical U-shaped arm constitutes the upper, middle, and lower constraint mechanisms to impose lateral constraints on the banana pseudostems. The powertrain consists of an engine, an automatic clutch, a driveshaft, and a helical gear. The cutting device is composed of the tool apron and blade.

Operation METHOD OF THE BaNANA PSEUdOSTEM CHOPPER. First, one pushes the chute handle [shown in Fig. l (5)] to move the pseudostem holding mechanism forward until the pseudostem is positioned in the $\mathrm{U}$-shaped arm. Then, one starts the engine; the cutting tool shaft of the cutting device drives the blade to rotate and cut the pseudostem to separate the pseudostem from the root stubble. Eventually, the banana pseudostem falls naturally due to gravity and is crushed by the blade. The operation is complete when the whole pseudostem has been chopped.

EXPERIMENT ON THE EFFECT OF THE BLADE TYPE ON THE CUTTING PERFORMANCE. There are various types of cutting blades, including the flail-shaped blade, whip-shaped blade, straight-blade, and so on. In the process of cutting and crushing, the flail-shaped blade cuts the stalks into the crushing chamber, in which the stems are smashed by the blades mounted on a rotating drum. Flailshaped blades have a better cutting and crushing effect on the toughened stalks, such as corn and sugarcane (Shang et al., 1998). The whipshaped blades have a relatively high rotational speed. These can break the ground while cutting and crushing crops, so that chopped stems can be mixed with the soil as much as possible, to meet the requirements of notill sowing (Zhang et al., 2004). The design of a straight-shaped blade is

Table 1. Main technical parameters of the banana pseudostem chopper engine.

\begin{tabular}{lclc}
\hline Parameter $^{\mathrm{z}}$ & Value & \multicolumn{1}{c}{ Parameter $^{\mathrm{z}}$} & Value \\
\hline Rated power $(\mathrm{kW})$ & 4.6 & Maximun torque $(\mathrm{N} \cdot \mathrm{m})$ & 15.6 \\
Idle speed $(\mathrm{rpm})$ & $1800 \pm 150$ & Cylinder bore $\times$ stroke $(\mathrm{mm})$ & $75 \times 57$ \\
Displacement $\left(\mathrm{cm}^{3}\right)$ & 252 & Compression ratio & $8.6: 1$ \\
Net weight $(\mathrm{kg})$ & 16.5 & Size $(\mathrm{mm})$ & $365 \times 285 \times 370$ \\
\hline
\end{tabular}

${ }^{\mathrm{z}} 1 \mathrm{~kW}=1.3410$ horsepower, $1 \mathrm{~cm}^{3}=0.0610 \mathrm{inch}^{3}, 1 \mathrm{~kg}=2.2046 \mathrm{lb}, 1 \mathrm{~N} \cdot \mathrm{m}=0.7375 \mathrm{lbfft}, 1 \mathrm{~mm}=0.0394$ inch. 
relatively simple. But because the blade is short, it is easily affected by the cutting resistance when cutting and crushing stalks. The result is an increase in the slip-cutting angle. (The cutting surface is inclined to the material axis, but the cutting direction is perpendicular to the material axis.) The angle increase thus reduces the cutting and crushing effect, and reduces the cutting efficiency (Guo et al., 2014). In general, the straightshaped blade is suitable for wheat, rice (Oryza sativa), and other crops with a certain degree of stem toughness (Gupta and Oduori, 1992).

In view of the performance of the above blades, L-shaped blades and arc-shaped blades were designed based on the straight-shaped blade and combined with the design characteristics of other blades, as shown in Fig. 2.

Before testing, the cutting blades were bolted to the cutter shaft. The feeding angles of the blades were set to $0^{\circ}$. Then reflective paper was adhered to the blades, and the tachometer was fixed in a stable position. The laser transmitting and receiving positions of the tachometer were maintained at $100 \mathrm{~mm}$ from the reflective paper on the cutter shaft [shown in Fig. 1 (7)], and the sampling rate was set to $10 \mathrm{~Hz}$. Finally, the rotation speed of the cutter shaft was measured and adjusted. By adjusting the engine's speed, the rotation speed of the cutter shaft was maintained at the optimal operating speed of $2000 \mathrm{rpm}$ (when the speed was less than 2000

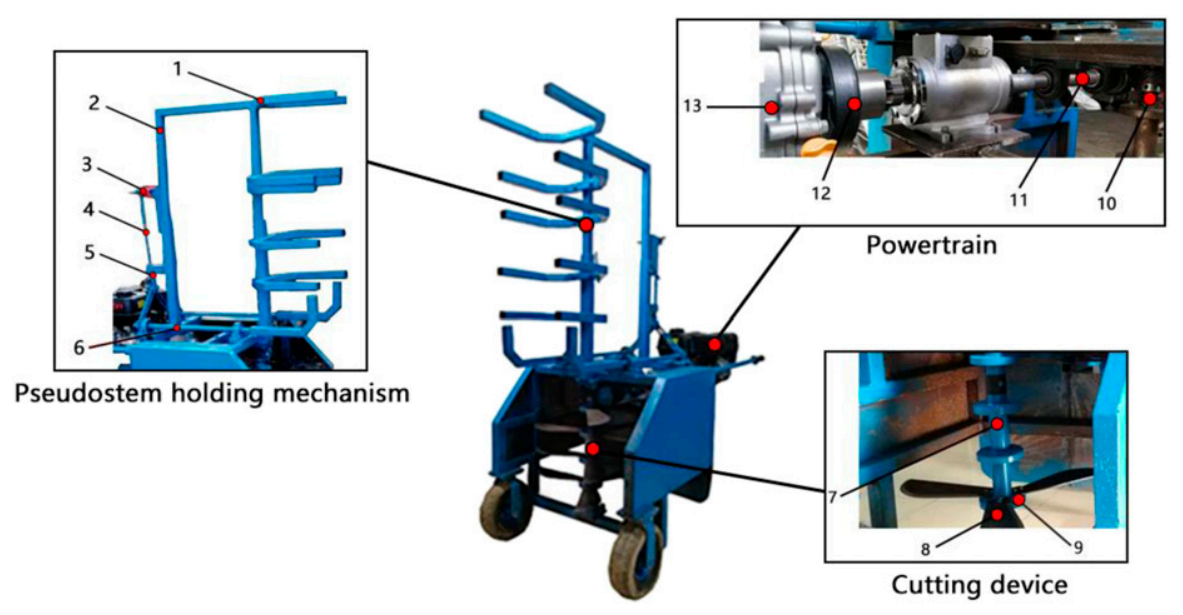

Fig. 1. Small vertical banana pseudostem chopper: (1) U-shaped arm, (2) telescopic rod, (3) shank slot, (4) guiding rod, (5) chute handle, (6) connecting rod, (7) cutter shaft, (8) blade, (9) tool apron, (10) helical gear, (11) driveshaft, (12) automatic clutch, (13) engine.
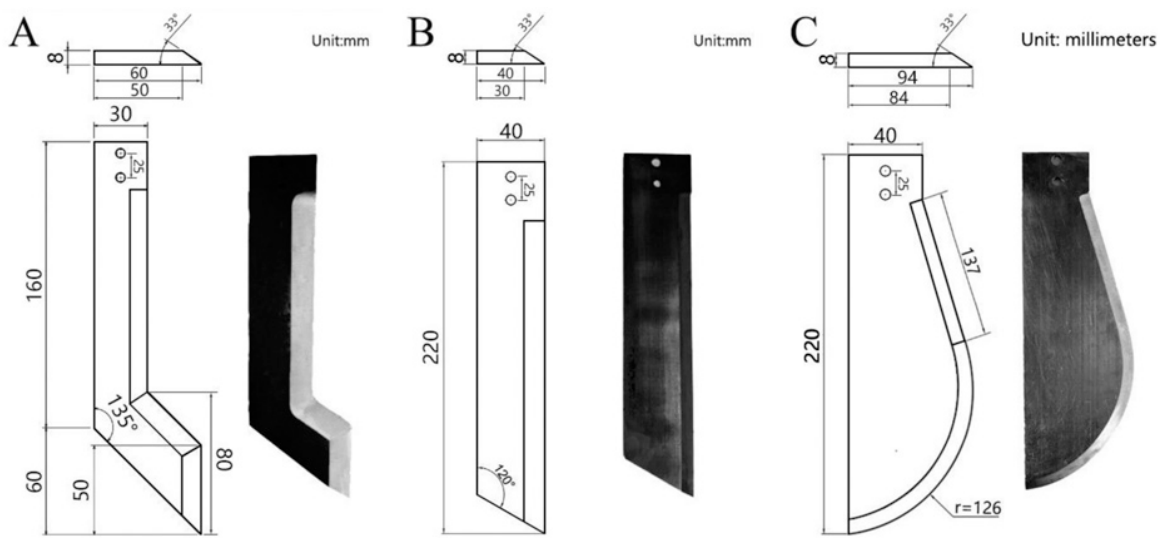

Fig. 2. The three blade types evaluated in the banana pseudostem chopper: (A) Lshaped blade, $(B)$ straight-shaped blade, $(C)$ arc-shaped blade; $1 \mathrm{~mm}=0.0394$ inch.

rpm, the engine speed was unstable and vulnerable to flameout). The output end of the engine was connected to one end of the dynamic torque sensor through coupling, and the other end was connected to the cutter shaft and gear shaft. The cutting torque on the blade was measured by a dynamic torque sensor (shown in Fig. 3). After processing the collected data, we determined the average torque on the blade. The average torque was calculated by Eq. [1], and the cutting force was calculated by Eq. [2]. The output power of the cutter shaft was measured by the dynamic torque sensor (the dynamic torque sensor can calculate the output power by measuring the torque and angular velocity, and the output power calculation is shown in Eq. [3]). The cutting power consumption $(\mathrm{P})$ of the banana pseudostem was calculated by Eq. [4].

The equation to calculate the average torque is as follows:

$$
\bar{M}=\frac{1}{n} \sum_{i=1}^{n} M_{i}
$$

where $\bar{M}$ is the average torque (Newton-meters); $M_{i}$ is the sampling point torque (Newton-meter); and $i=$ $1,2,3, \ldots, n$ is the number of samples collected.

The equation to calculate the average cutting force is as follows:

$$
\bar{F}=\bar{M} / L
$$

where $\bar{F}$ is the average cutting force (Newtons), $L$ is the distance between the blade tip and the center of blade rotation, and $L$ is equal to $0.22 \mathrm{~m}$.

The equation to calculate the output power is as follows:

$$
P_{1}=\omega \times \bar{M}=\frac{\pi n \bar{M}}{30}
$$

where $P_{1}$ is the output power of the cutter shaft (kilowatts); $\bar{M}$ is the average torque (Newton-meter); $\omega$ is the angular velocity (radians per second); and $n$ is the rotation speed (revolutions per minute; measured by the dynamic torque sensor).

The equation for the cutting power is as follows:

$$
P=\frac{P_{0}-P_{1}}{P_{0}}
$$

where $P$ is the cutting power (kilowatts); $P_{0}$ is the input power of the 
cutter shaft (kilowatts), i.e., the theoretical value of the cutting shaft power $\left(P_{0}=3.8 \mathrm{~kW}\right)$; and $P_{1}$ is the output power of the cutter shaft

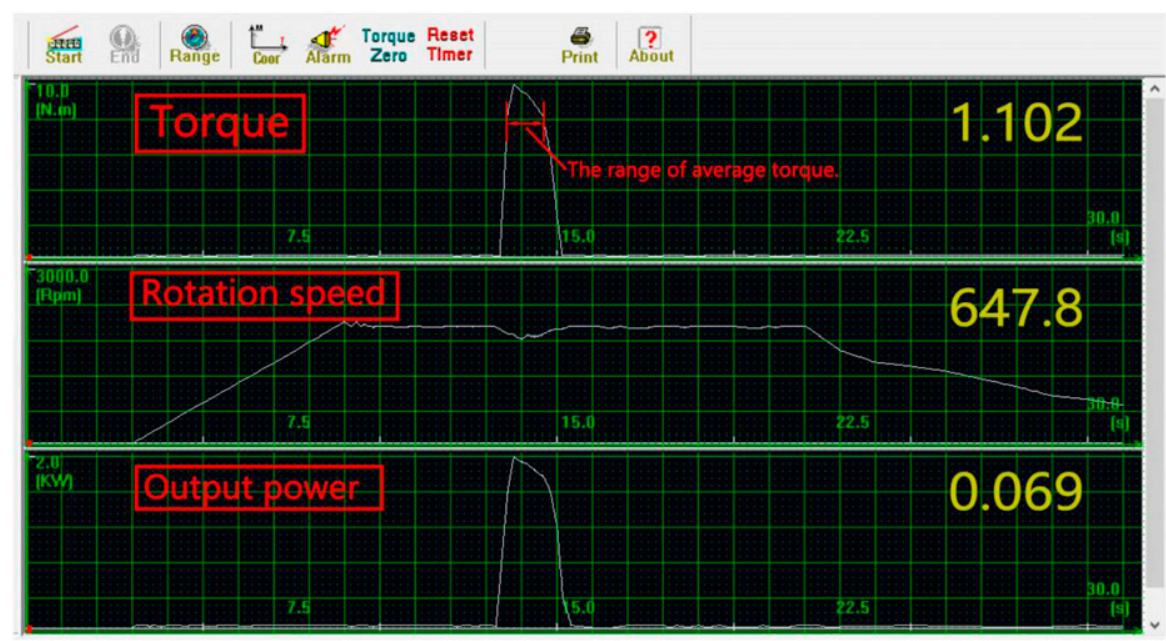

Fig. 3. Software interface for the dynamic torque sensor of the banana pseudostem chopper. In the process of crushing banana pseudostem, the torque, rotation speed, and output power are measured and recorded by the dynamic torque sensor.
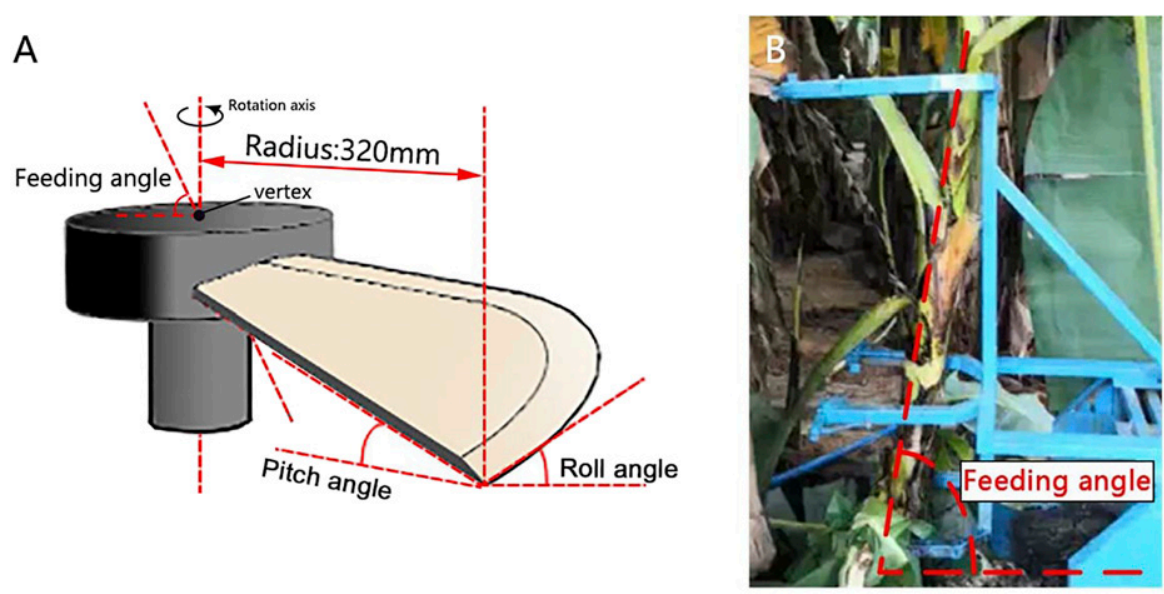

Fig. 4. Installation angles of the blade in the banana pseudostem chopper. The feeding angle in (A) corresponds to (B), and the vertex of the feeding angle is on the axis of the tool apron; $1 \mathrm{~mm}=0.0394$ inch.
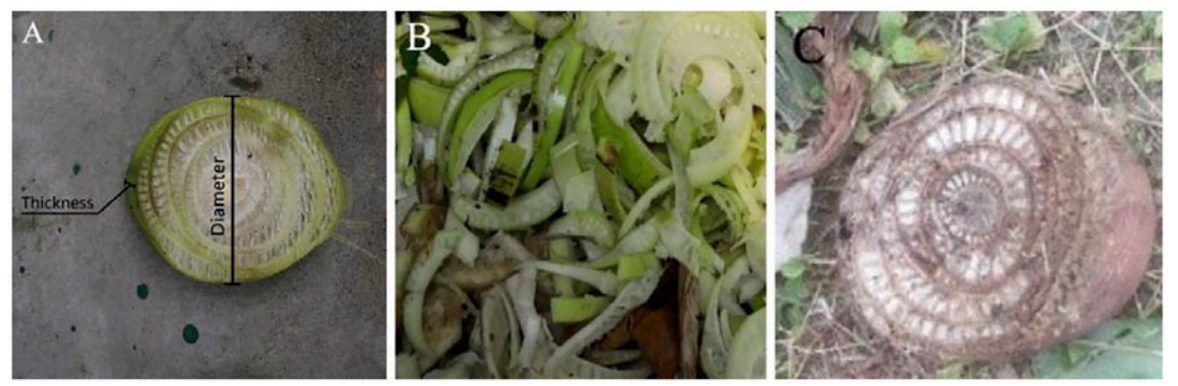

Fig. 5. Effects of the banana pseudostem chopping. (A) Measurement of the chopped pseudostem size, (B) qualified banana pseudostem, (C) unqualified banana pseudostem.
EXPERIMENT ON THE EFFECTS OF THE KEY OPERATING PARAMETERS ON THE CUTTING PERFormance. The installation angle of the blade has two different angles: roll angle and pitch angle, as shown in Fig. 4. The feeding angle is shown in Fig. 4. To explore the effects of the roll angle, pitch angle, and feeding angle on the cutting performance, an experiment was conducted to determine the crushing qualification rate and crushing efficiency of the banana pseudostem.

According to preliminary experiments, the roll angles were set as $0^{\circ}$, $6^{\circ}, 12^{\circ}, 18^{\circ}$, and $24^{\circ}$, the pitch angles were set as $-10^{\circ},-5^{\circ}, 0^{\circ}, 5^{\circ}$, and $10^{\circ}$, and the feeding angles were set as $0^{\circ}$, $5^{\circ}, 10^{\circ}, 15^{\circ}$, and $20^{\circ}$. There were 15 experiments in total, each of which was repeated three times. The average qualification rate Eq. [5] and crushing efficiency Eq. [6] of each group of experiments were obtained. During the preliminary experiment investigating the roll angle, when the roll angle was negative, the problem of knife sticking (the blade getting stuck in the pseudostem) easily occurred, and the banana pseudostem was difficult to cut and crush. Therefore, the roll angle was set to be positive during the experiments. Before the experiment, the blade was adjusted to the experimental angle, and a protractor was used for the calibration. Then the cutter shaft was adjusted to the optimal operating speed of $2000 \mathrm{rpm}$. After the banana pseudostem had been crushed, the crushing qualification rate and crushing efficiency were calculated according to Eq. [5] and Eq. [6], respectively. Because the upper part of the pseudostems is generally small, and the bottom is large, the sampling unit volume is calculated according to the shape of a truncated cone. All uncrushed pseudostems were calculated according to the shape of a truncated cone; then all calculated results were added to obtain the sum of the uncrushed volumes.

The crushing qualification rate is

$$
Q=\left(1-\frac{v}{V}\right) \times 100 \%
$$

where $Q$ is the crushing qualification rate (percent), $v$ is the sum of the uncrushed volumes (cubic meter), and $V$ is the sampling unit volume (cubic meter).

The qualification of crushing was determined as follows. Most of the banana pseudostems were converted 
to fine filaments after crushing. If the thickness was more than $1.5 \mathrm{~cm}$ after crushing, then it was determined to be unqualified; i.e., not completely shredded, as shown in Fig. 5.

The crushing efficiency is

$$
E=\frac{V-v}{T} \times 100 \%
$$

where $E$ is the crushing efficiency (cubic meters per hour), and $T$ is the time required for crushing (hours).

EXPERIMENT ON THE VARIATION CHARACTERISTICS OF DECOMPOSING BANANA PSEUDOSTEMS. The decomposition characteristics of the banana
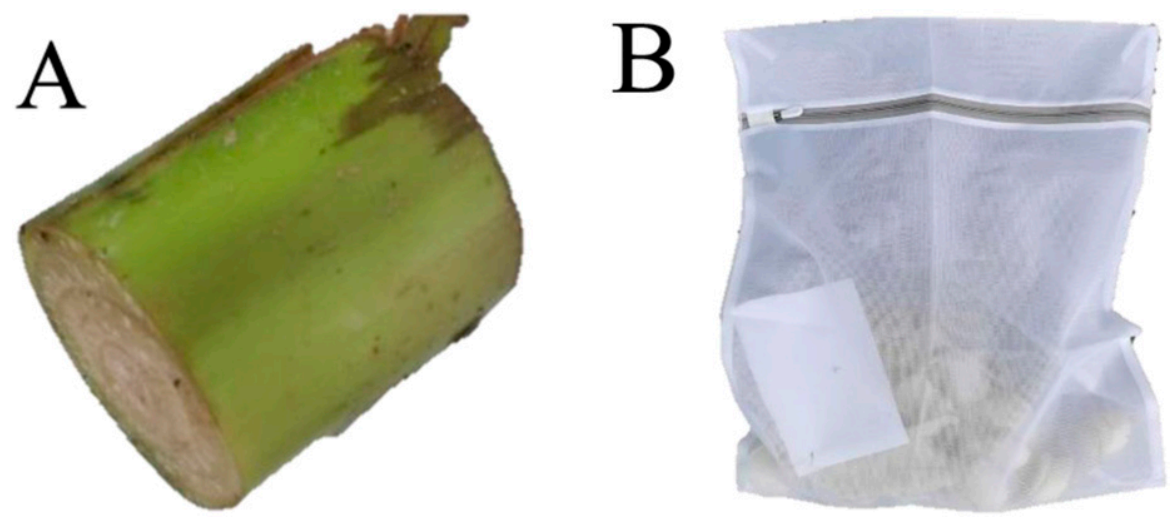

Fig. 6. Examples of two kinds of decomposition test samples. (A) Test sample of a naturally decomposing banana pseudostem. (B) Test sample of a banana pseudostem after being chopped and collected in a mesh bag.

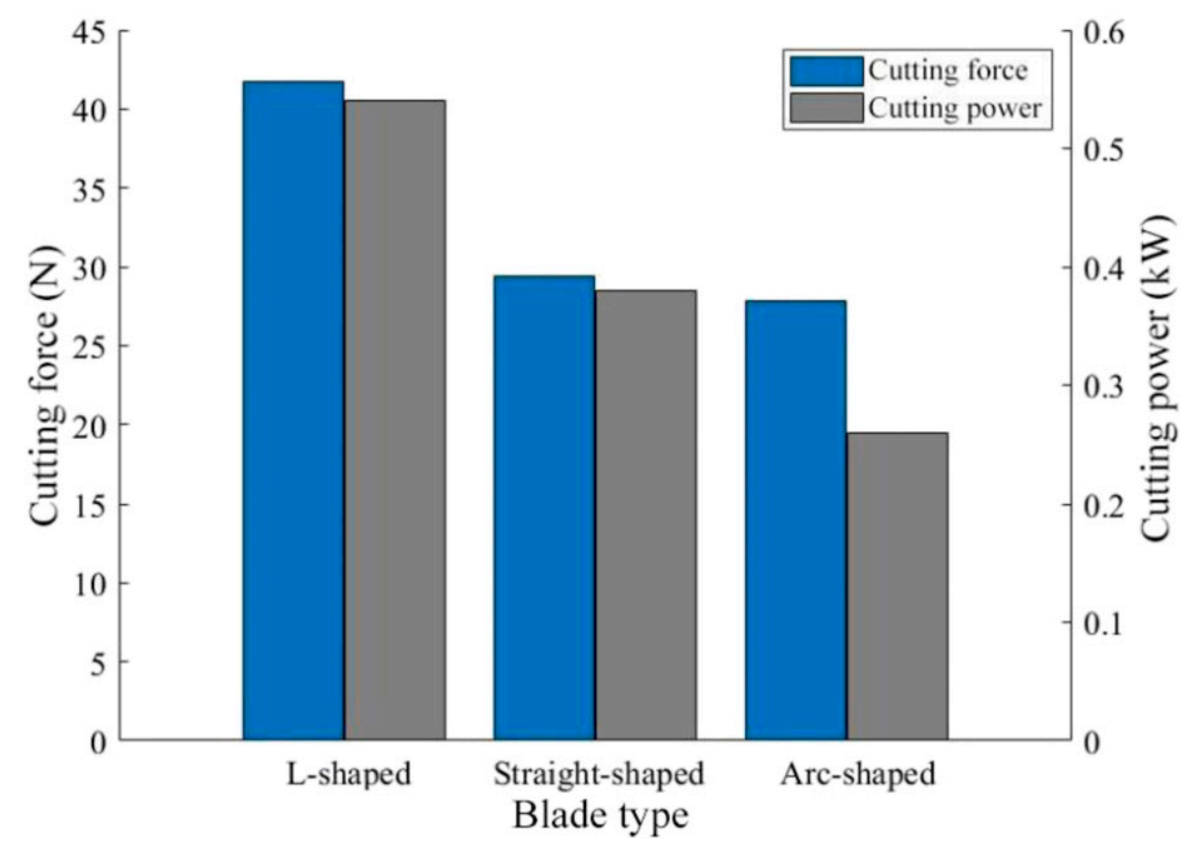

Fig. 7. Effect of the blade type on the cutting force and cutting power consumption of banana pseudostem, including the L-shaped blade, straightshaped blade, and arcshaped blade. Roll angle $=0^{\circ}$; pitch angle $=0^{\circ}$; feeding angle $=0^{\circ} ; 1 \mathrm{~N}=0.2248 \mathrm{lbf}, 1 \mathrm{~kW}=1.3410$ horsepower. addition, 11 segments of the pseudostem (each of which had a weight of $300 \mathrm{~g}$ ) were taken and placed into nylon mesh bags. Weighing measurements were made on days 5,10 , 15, and 20. Eq. [7] and Eq. [8] were used to calculate the weight reduction rate and average decomposition rate.

The weight reduction rate is

$$
\Delta m=\frac{m_{0}-m_{n}}{m_{0}}
$$

and the average decomposition rate is

$$
\Delta v=\frac{m_{c}-m_{b}}{x}
$$

where $\Delta m$ is the weight reduction rate (grams per day); $m_{0}$ is the initial weight of the pseudostem (grams); $m_{n}$ is the weight of the pseudostem after $n$ days (grams); $m_{c}$ is the current pseudostem weight (grams); $m_{b}$ is the previously measured weight of the pseudostem (grams); $x$ is the number of days between measurements, and $x$ $=5$ in this article.

\section{Results and discussion}

EFFECT OF THE BLADE TYPE ON THE CUTTING PERFORMANCE. The experiments with three blade types showed that the L-shaped blade had the highest cutting force and cutting power consumption $(41.76 \mathrm{~N}$ and $0.54 \mathrm{~kW}$, respectively). The arc-shaped blade had the lowest values $(27.83 \mathrm{~N}$ and $0.26 \mathrm{~kW}$, respectively). The experimental results are shown in Fig. 7. An arc-shaped blade reduces the cutting force and cutting power consumption, which plays an important role in improving both the crushing qualification rate and crushing efficiency of the banana pseudostem chopper. During the cutting process, the L-shaped and straight-shaped blades have disadvantages such as a high cutting resistance and larger vibration. The cutter shaft torque of the arc blade is more uniform, which can effectively reduce the cutting power and improve the cutting quality.

EFFECTS OF THE KEY OPERATING PARAMETERS AND THE ROLL ANGLE ON THE CUTTING PERFORMANCE. The relationship between the roll angle $(x)$ and the crushing qualification rate $(y)$ was fitted by a second-order polynomial with statistical software (IBM SPSS Statistics version 22; IBM Corp., 
Armonk, NY) as follows: $y=-0.18 x^{2}+$ $4.19 x+64.768$, and the analysis of variance (ANOVA) table is shown in Table 2 , where $P=0.0005$ and $R^{2}=$ 0.717 , which indicates that the roll angle significantly affected the crushing qualification rate (Fig. 8). The size of the roll angle is related to the size of the cutting section. A larger roll angle corresponds to a larger angle of deviation from the blade cutting section to the axis of the pseudostem; thus, the cutting section is larger. The size of the cutting section of the pseudostem after crushing is the basis for determining the qualification of the crushing. Figure 8 shows that with an increase in roll angle, the crushing qualification rate first increases, subsequently decreases, and reaches its maximum value at $\approx 12^{\circ}$.
The microscopic structure of the banana pseudostem was mainly composed of parenchyma, spongy tissue, vascular bundles, and other fibrous substances. The direction of the fiber is parallel to the axis of the center of the pseudostem. Considering the cutting resistance relative to the direction of the fiber, the cutting strength of the pseudostem is different when the pseudostem is vertically cut vs. at a certain angle. At $0^{\circ}$, the cutting direction and cutting plane are perpendicular to the central axis of the pseudostem, and the cutting strength is maximal, so the cutting resistance is maximal (Guo et al., 2014). When the blade inclines at a certain angle, the axis of the pseudostem center is inclined to the cutting plane, and the cutting resistance

Table 2. One-way analysis of variance of different angles and crushing qualification rates of the banana pseudostem chopper.

\begin{tabular}{clrrrrr}
\hline Factor & & $\begin{array}{c}\text { Sum of } \\
\text { squares }\end{array}$ & df & $\begin{array}{c}\text { Mean } \\
\text { square }\end{array}$ & F & $\boldsymbol{P}$ \\
\hline Roll & Between groups & 1789.070 & 2 & 894.535 & 15.169 & 0.0005 \\
angle & Within groups & 707.646 & 12 & 58.970 & & \\
& Total & 2496.716 & 14 & & & \\
Pitch & Between groups & 476.761 & 2 & 238.381 & 63.308 & 0.0000 \\
angle & Within groups & 45.185 & 12 & 3.765 & & \\
& Total & 521.947 & 14 & & & \\
Feeding & Between groups & 6.858 & 2 & 3.429 & 18.557 & 0.0002 \\
angle & Within groups & 2.217 & 12 & 0.185 & & \\
& Total & 9.075 & 14 & & & \\
\hline
\end{tabular}

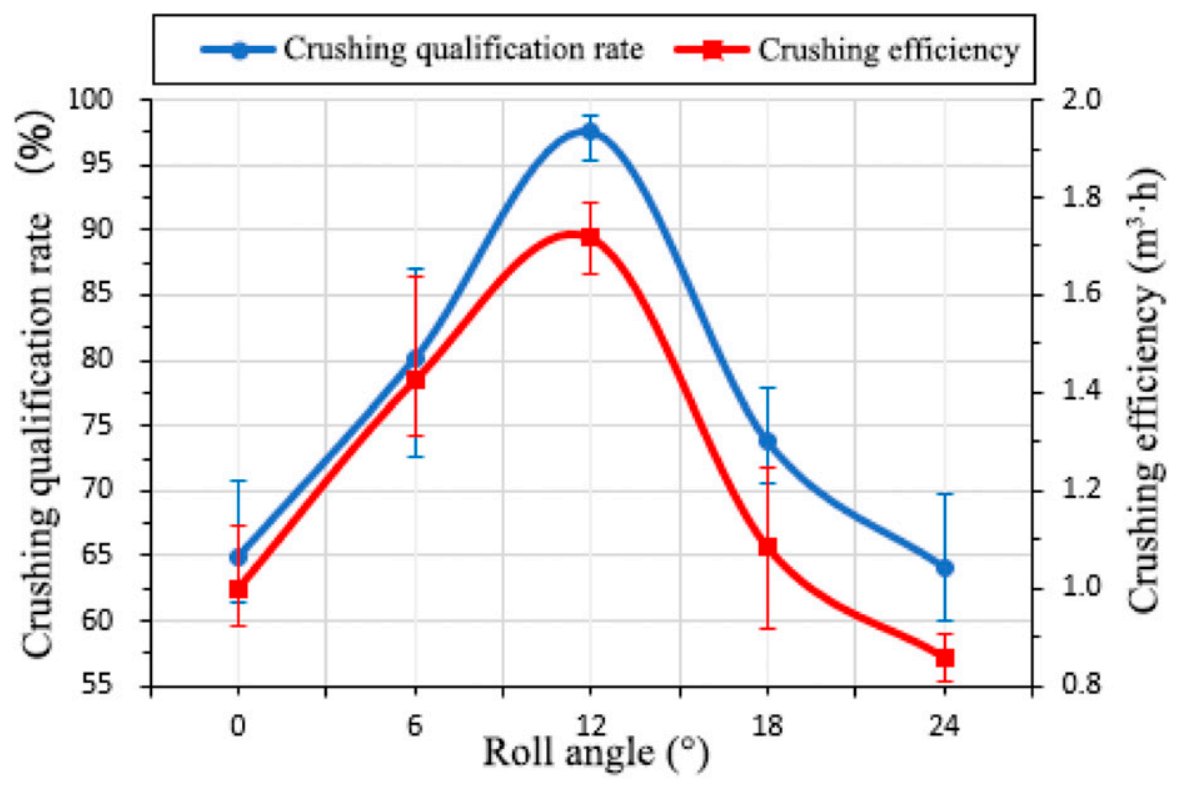

Fig. 8. Effect of the roll angle on the cutting performance of banana pseudostem. Crushing qualification rate and crushing efficiency are two indexes of cutting performance. The factors evaluated are the crushing qualification rate and crushing efficiency; pitch angle $=0^{\circ}$; feeding angle $=0^{\circ} ; 1 \mathrm{~m}^{3}=35.3147 \mathrm{ft}^{3}$. is significantly reduced, which is conducive to the cutting of the blade and improves the crushing qualification rate. Therefore, the crushing qualification rate is maximal at $\approx 12^{\circ}$. However, with the increase in roll angle, the cutting section gradually increases, so the crushing qualification rate tends to decrease.

The relationship between roll angle $(x)$ and crushing efficiency $(y)$ was fitted by a second-order polynomial with statistical software (IBM SPSS Statistics version 22) as follows: $y=-0.004 x^{2}+0.096 x+0.96$, and the ANOVA table is shown in Table 3 , where $P=0.0004$ and $R^{2}=0.726$, which indicates that the roll angle very significantly affects the crushing efficiency. The experimental results in Fig. 8 show that when the roll angle is $0^{\circ}$ to $12^{\circ}$, the crushing efficiency increases with increasing roll angle. When the roll angle is $12^{\circ}$, the crushing efficiency decreases. This change occurs because when the roll angle is $0^{\circ}$, both the cutting direction and cutting surface are perpendicular to the direction of the pseudostem fiber, and the shear strength of the pseudostem is maximal. When the cutting direction and cutting surface deviate from the axis of the pseudostem by a certain angle, the cutting resistance eventually decreases, which improves the crushing efficiency. Therefore, the crushing efficiency will increase with an increase in roll angle over a certain range. However, when the roll angle increases to a certain value, the pressure of the pseudostem on the blade increases while the pseudostem falls, which increases the cutting resistance and decreases the crushing efficiency.

EFFECT OF THE BLADE PITCH ANGLE ON THE CUTTING PERformance. The relationship between the pitch angle $(x)$ and the crushing qualification rate $(y)$ was fitted by a second-order polynomial with statistical software (IBM SPSS Statistics version 22) as follows: $y=-0.093 x^{2}-0.579 x+$ 97.074, and the ANOVA table is shown in Table 2 , where $P<0.001$ and $R^{2}=0.913$, which indicates that the pitch angle very significantly affects the crushing qualification rate. As shown in Fig. 9, when the pitch angle is between $-10^{\circ}$ and $-5^{\circ}$, a higher absolute value of the angle corresponds to a lower crushing qualification rate. This behavior occurs because 
when the pitch angle is negative, the movement direction of the blade is from the bottom to the top, and the pseudostem keeps falling during the cutting process. A greater absolute value of the pitch angle corresponds to a greater gravity effect on the pseudostem, which must be overcome during the cutting operation of the blades; thus, the crushing efficiency decreases. When the pitch angle is $0^{\circ}$ to $10^{\circ}$, with a larger pitch angle, the crushing qualification rate shows a downward trend due to the size of the cutting section. When the pitch angle is $0^{\circ}$, the cutting surface is perpendicular to the axis of the pseudostem. At this moment, the shear strength of the pseudostem fiber is maximal; therefore, the crushing qualification rate is lower than that at a pitch angle of $-5^{\circ}$.

Table 3. One-way analysis of variance of different angles and crushing efficiencies of the banana pseudostem chopper.

\begin{tabular}{clcrccc}
\hline Factor & & $\begin{array}{c}\text { Sum of } \\
\text { squares }\end{array}$ & df & $\begin{array}{c}\text { Mean } \\
\text { square }\end{array}$ & F & $\boldsymbol{P}$ \\
\hline Roll angle & Between groups & 1.182 & 2 & 0.591 & 15.929 & 0.0004 \\
& Within groups & 0.445 & 12 & 0.037 & & \\
& Total & 1.627 & 14 & & & \\
Pitch & Between groups & 0.527 & 2 & 0.264 & 8.099 & 0.0059 \\
angle & Within groups & 0.390 & 12 & 0.033 & & \\
& Total & 0.917 & 14 & & & \\
Feeding & Between groups & 1.101 & 2 & 0.550 & 36.760 & 0.0000 \\
angle & Within groups & 0.180 & 12 & 0.015 & & \\
& Total & 1.281 & 14 & & & \\
\hline
\end{tabular}

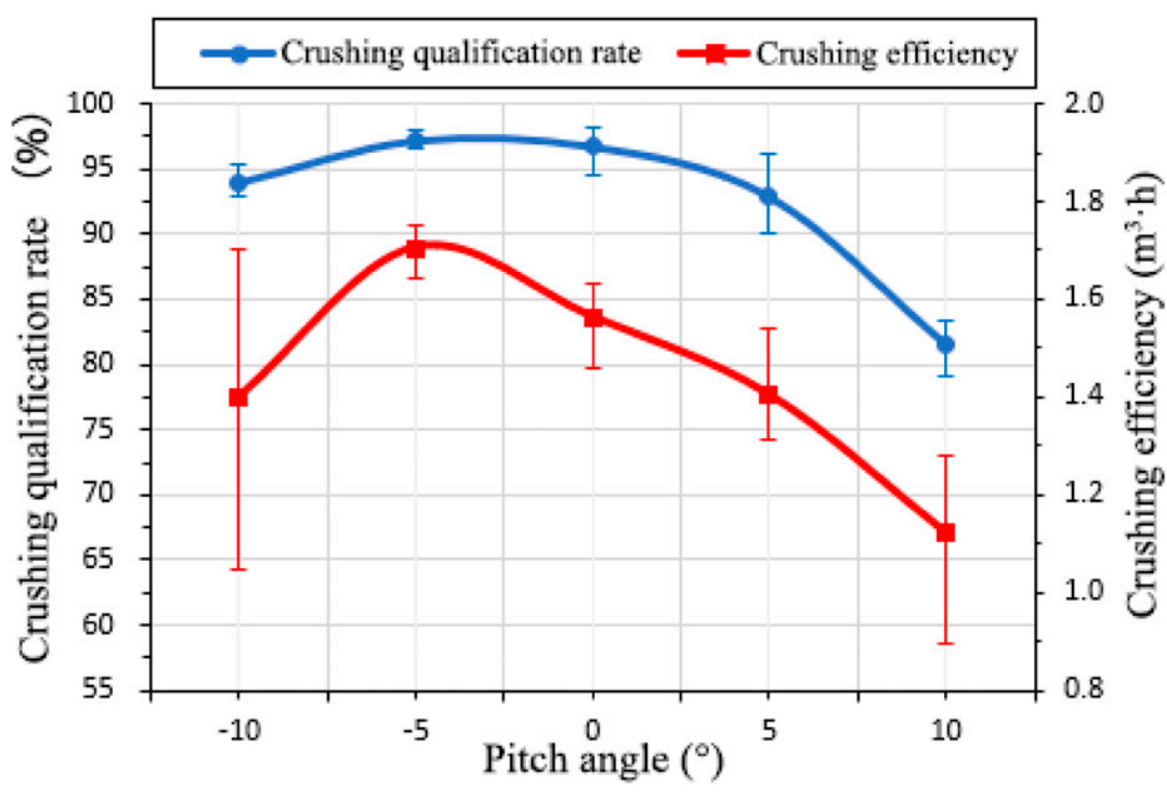

Fig. 9. Effect of the pitch angle on the cutting performance of banana pseudostem. Crushing qualification rate and crushing efficiency are two indexes of cutting performance. The factors evaluated are the crushing qualification rate and crushing efficiency; roll angle $=0^{\circ}$; feeding angle $=0^{\circ} ; 1 \mathrm{~m}^{3}=35.3147 \mathrm{ft}^{3}$.
The pitch angle is greater than $0^{\circ}$, and the movement direction of the blade is from top to bottom. In the falling process, the pseudostem had contact with the back of the blade, and the blade was not fully used to cut the pseudostem. Therefore, the crushing efficiency decreases with increasing pitch angle. When the pitch angle is $0^{\circ}$, the shear strength of the pseudostem fiber is maximal, and the cutting resistance increases. Therefore, compared with the pitch angle of $-5^{\circ}$, the crushing efficiency decreased compared with when the pitch angle was $0^{\circ}$.

EFFECT OF THE FEEDING ANGLE ON THE CUTTING PERformance. The relationship between the feeding angle $(x)$ and the crushing qualification rate $(y)$ was fitted by a second-order polynomial with statistical software (IBM SPSS Statistics version 22) as follows: $y=-0.11 x^{2}+0.155 x+$ 97.643, and the ANOVA table is shown in Table 2 , where $P=0.0002$ and $R^{2}=0.756$, which indicates that the feeding angle very significantly affects the crushing qualification rate. The experimental results in Fig. 10 show that the crushing qualification rate is maximal $(98.27 \%)$ when the feeding angle is $5^{\circ}$. A certain feeding angle is helpful to reduce the cutting resistance and facilitate the crushing of the pseudostem. Therefore, when the feeding angle is $5^{\circ}$, the crushing qualification rate increases compared with when its value is $0^{\circ}$. However, with increasing feeding angle, the cutting section gradually increases, so the crushing qualification rate decreases.

The relationship between the feeding angle and the crushing efficiency was fitted by a second-order polynomial with statistical software (IBM SPSS Statistics version 22) as follows: $y=-0.004 x^{2}+0.039 x+$ 1.586, and the ANOVA table is shown in Table 3 , where $P<0.001$ and $R^{2}=0.860$, which indicates that the feeding angle very significantly affects the crushing efficiency. The experimental results in Fig. 10 show that when the feeding angle is $5^{\circ}$, the crushing efficiency is the highest at $1.756 \mathrm{~m}^{3} \cdot \mathrm{h}^{-1}$. The increase in feeding angle reduces the cutting resistances and facilitates crushing of the pseudostem. However, a larger feeding angle corresponds to a lower falling speed of the pseudostem compared with when the feeding angle is $0^{\circ}$, which affects the crushing efficiency. 


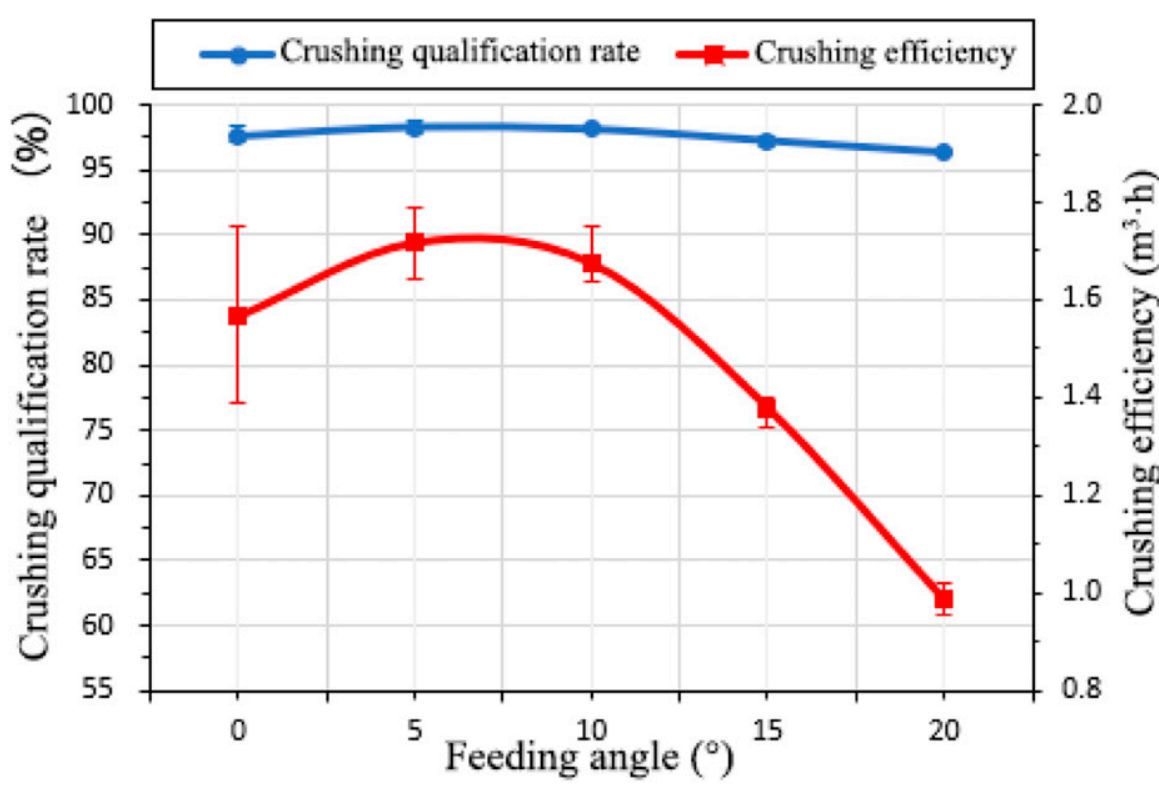

Fig. 10. Effect of the feeding angle on the cutting performance of banana pseudostem. Crushing qualification rate and crushing efficiency are two indexes of cutting performance. The factors evaluated are the crushing qualification rate and crushing efficiency. Roll angle $=0^{\circ}$, feeding angle $=0^{\circ} ; 1 \mathrm{~m}^{3}=35.3147 \mathrm{ft}^{3}$.

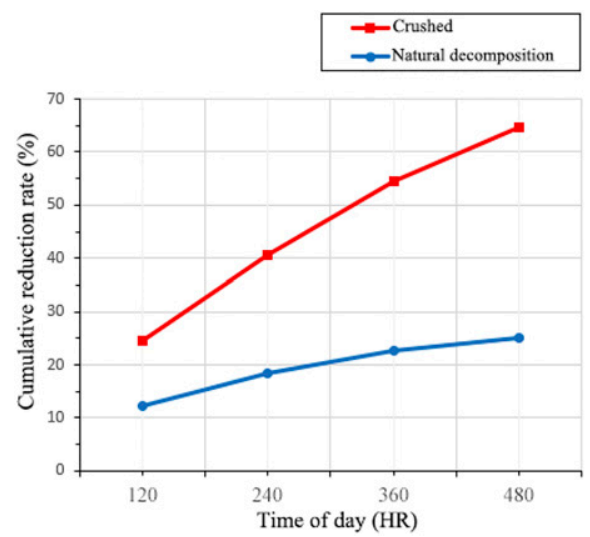

Fig. 11. Weight reduction rate of the banana pseudostem and average decomposition rate of the banana pseudostem. Roll angle $=0^{\circ}$; pitch angle $=0^{\circ}$; feeding angle $=0^{\circ} ; 1 \mathrm{mg}=3.5274 \times 10^{-5} \mathrm{oz}$.

Therefore, after the crushing efficiency reaches the maximum value at $5^{\circ}$, the crushing efficiency gradually decreases with increasing feeding angle.

VARIATION CHARACTERISTICS OF A DECOMPOSING BANANA PSEUDOSTEM. According to these experimental results, the operating parameters of the chopper for the tests of the decomposition characteristics of the banana pseudostem were a pitch angle of $-5^{\circ}$, a roll angle of $12^{\circ}$, and a feeding angle of $5^{\circ}$; and the arc-shaped blade was selected. The experimental results in Fig. 11 show that the weight reduction rate and average decomposition rates of the crushed pseudostem were

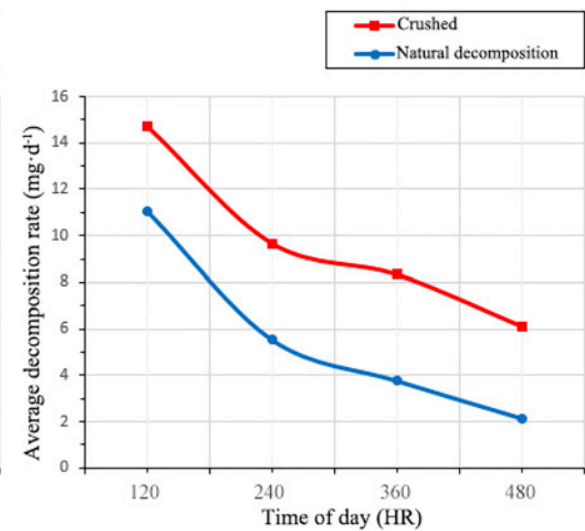

\section{Conclusions}

In this article, the cutting force, cutting power, crushing qualification rate, crushing efficiency, weight reduction rate, and average decomposition rate were evaluated. The effects of key operating parameters on banana pseudostem crushing were explored.

This work draws the following five conclusions through experimental analysis: 1) An arc-shaped blade had the lowest cutting force and cutting power consumption $(27.83$ $\mathrm{N}$ and $0.26 \mathrm{~kW}$, respectively). 2) When the roll angle was $\approx 12^{\circ}$, the crushing qualification rate and crushing efficiency reached their maximum values of $97.57 \%$ and $1.718 \mathrm{~m}^{3} \cdot \mathrm{h}^{-1}$, respectively. 3) When the pitch angle was about $-5^{\circ}$, the crushing qualification rate and crushing efficiency reached their maximum values of $97.13 \%$ and $1.705 \mathrm{~m}^{3} \cdot \mathrm{h}^{-1}$, respectively. 4) When the feeding angle was $\approx 5^{\circ}$, the crushing qualification rate and crushing efficiency reached their maximum values of $98.27 \%$ and 1.756 $\mathrm{m}^{3} \cdot \mathrm{h}^{-1}$, respectively. 5) The weight reduction rate and average decomposition rate of the crushed banana pseudostem were 2.73 times and 3.61 times greater than those of its natural decomposition, respectively.

In this article, the experimental results using angle parameters as a single experimental factor showed that there are optimal crushing effect values for the roll angle, pitch angle, and feeding angle, respectively. During follow-up studies, orthogonal experimental studies on the roll angle, pitch angle, and feeding angle of different varieties of bananas can be considered to obtain the optimal combination value of angle parameters of each variety of bananas, to provide a reference basis for commercial practice.

weight after $20 \mathrm{~d}$ is 2.73 times greater than that of natural decomposition, and its average decomposition rate is 3.61 times greater than its natural decomposition rate. During the process of decomposition, the pseudostem showed the characteristics of fast decomposition during the early stage and slow decomposition during the later stage. After crushing, compared with the naturally decomposing pseudostem, the pseudostem had a smaller volume; and because it was directly exposed to air, this was beneficial for accelerating the decomposition rate.

\section{Literature cited}

Akdemir, B. 2013. Agricultural mechanization in Turkey. IERI Procedia 5:41-44, doi: 10.1016/j.ieri.2013.11.067.

Bakeer, B., I. Taha, H. El-Mously, and S.A. Shehata. 2013. On the characterization of structure and properties of sorghum stalks. Ain Shams Eng. J. 4(2):265-271, doi: $10.1016 /$ j.asej.2012.08.001

Basak, S., S. Saxena, S. Chattopadhyay, R. Narkar, and R. Mahangade. 2015. Banana 
pseudostem sap: A waste plant resource for making thermally stable cellulosic substrate. J. Ind. Text. 46(4):1003-1023, doi: $10.1177 / 1528083715591580$.

Chen, Y., J.L. Gratton, and J. Liu. 2004. Power requirements of hemp cutting and conditioning. Biosyst. Eng. 87(4):417424, doi: 10.1016/j.biosystemseng. 2003 . 12.012 .

Duval, A., A. Bourmaud, L. Augier, and C. Baley. 2011. Influence of the sampling area of the stem on the mechanical properties of hemp fibers. Mater. Lett. 65(4): 797-800, doi: 10.1016/j.matlet.2010. 11.053 .

Gupta, C.P. and M.F. Oduori. 1992. Design of the revolving knife-type sugarcane basecutter. Trans. Amer. Soc. Agr. Biol. Eng. 35(6):1747-1752, doi: 10. $13031 / 2013.28793$.

Ghahraei, O., D. Ahmad, A. Khalina, H. Suryanto, and J. Othman. 2011. Cutting tests of kenaf stems. Trans. Amer. Soc. Agr. Biol. Eng. 54(1):51-56, doi: 10.13031/ 2013.36252.

Guo, X., X. Zhang, Y. Xu, P. Li, C. Chen, and $\mathrm{S}$. Wu. 2014. Design and experiment of cutting blade for cane straw. Trans. Chin. Soc. Agr. Eng. 30(24):47-53, doi: 10.3969/j.issn.1002-6819.2014.24.006.

Huang, W., H.L. Qin, Y. Lu, B. Li, X. Tang, C. Wang, Y. Yan, and J.Q. Ou. 2020. Effects of banana stem and its biochar application on soil aggregate characteristics in the Pearl River Delta. Chin. J. Eco Agr. 28(3):413-420, doi: 10.13930/ j.cnki.cjea.190695.

Igathinathane, C., A.R. Womac, S. Sokhansanj, and S. Narayan. 2009. Bioenergy size reduction of high- and lowmoisture corn stalks by linear knife grid system. Biomass Bioenergy 33(4):547557, doi: 10.1016/j.biombioe.2008. 09.004 .

Igathinathane, C., A.R. Womac, and S. Sokhansanj. 2010. Corn stalk orientation effect on mechanical cutting. Biosyst.
Eng. 107(2):97-106, doi: 10.1016/ j.biosystemseng.2010.07.005.

Igathinathane, C., L.O. Pordesimo, M.W. Schilling, and E.P. Columbus. 2011. Fast and simple measurement of cutting energy requirement of plant stalk and prediction model development. Ind. Crops Prod. 33(2):518-523, doi: 10.1016/j. indcrop.2010.10.015.

Kakahy, A.N.N., D. Ahmad, A. Hamid, S. Sulaiman, and I. Aris. 2013. Effects of knife shapes and cutting speeds of a mower on the power consumption for pulverizing sweet potato vine. Key Eng. Mater. 594/595:1126-1130, doi: 10.4028/ www.scientific.net/KEM.594-595. 1126.

Kakahy, A.N.N., D. Ahmad, M.D. Akhir, S. Sulaiman, and A. Ishak. 2014. Effects of rotary mower blade cutting angles on the pulverization of sweet potato vine. Agr. Agr. Sci. Procedia 2:95-101, doi: 10.1016/j.aaspro.2014.11.014.

Liu, J., J. Li, and Z. Yang. 2014. Review current status of postharvest handling equipment for banana. J. Agr. Mechaniz. Res. 36(11):249-252+257, doi:10.13427/ j.cnki.njyi.2014.11.058.

Li, H., C. Wang, H. Sun, X. Yan, and Q. Liang. 2017. Comprehensive utilization and sustainable development of agriculture straw. J. Agr. Mechaniz. Res. 39(8):256-262, doi: 10.13427/j.cnki. njyi.2017.08.054.

Mathanker, S.K., T.E. Grift, and A.C. Hansen. 2015. Effect of blade oblique angle and cutting speed on cutting energy for energycane stems. Biosyst. Eng. 133:64-70, doi: 10.1016/j.biosystemseng. 2015.03.003.

Ozbay, N., A.S. Yargic, R.Z.Y. Sahin, and E. Yaman. 2019. Valorization of banana peel waste via in situ catalytic pyrolysis using Al-Modified SBA-15. Renew. Energy 140:633-646, doi: 10.1016/j.renene. 2019.03.071.

Raymundo, S.O., B.H. Patricia, R.M. Gabriela, U.N. Fernando, O. Juan, L.L.
Violeta, N.F. Ramirez, E.B.D. Carlos, and C.V. Pablo. 2014. Characterization of lignocellulosic fruit waste as an alternative feedstock for bioethanol production. BioResources 9(2):1873-1885, doi: 10.15376/biores.9.2.1873-1885.

Siemens, M.C., D.E. Wilkins, and R.F. Correa. 2003. Development and evaluation of a residue management wheel for hoe-type no-till drills. Trans. Amer. Soc. Agr. Biol. Eng. 47(2):397-404, doi: $10.13031 / 2013.16033$.

Shang, S., H. Meng, W. Yu, and Z. Yuan. 1998. Design and research of flail throw cuts for corn stalk. Trans. Chi. Soc. Agr. Eng. 14(2):82-85, doi: 10.3321/ j.issn:1002-6819.1998.02.017.

Wang, C., X. Zhang, Y. Li, and D. Liang. 2017. Design of the pre-cutting combined type of banana stalk chopper. J. Agr. Mechaniz. Res. 39(6):111-114,119, doi: 10.13427/j.cnki.njyi.2017.06.022.

Zhu, D., Y. Chang, L. Liang, W. Zhang, and T. Zhou. 2011. Recycling process research and mechanical structural design of banana stalk \& root-stubble. J. Agr. Mechaniz. Res. 33(9):136-138, 142, doi: 10.3969/j.issn.1003-188X.2011. 09.034 .

Zhang, J. 2019. Design and experiment on the machine of banana tree chopped and recycling. J. Agr. Mechaniz. Res. 41(9):157-162, doi: 10.13427/j.cnki.njyi. 2019.09 .029

Zhang, S., S. Zhao, Y. Ma, J. Li, J. Li, and X. Zhang. 2004. Research on scourgetype reamer used for straw returning machine. Trans. Chi. Soc. Agr. Machinery 2:59-61, doi: 10.3969/j.issn.1000-1298. 2004.02.017.

Zhang, X., Z. Wang, Y. Li, and D. Liang. 2018. Design and experiment of slidingcutting and anti-twining returning device for banana straw. Trans. Chi. Soc. Agr. Eng. 34(3):26-34, doi: 10.11975/j.issn. 1002-6819.2018.03.004. 